\title{
O ACESSO À JUSTIÇA COMO DIREITO FUNDAMENTAL
}

\author{
José Celso Martins*
}

\section{RESUMO}

O presente artigo foi realizado por meio de pesquisas de legislações e obras bibliográficas da área do direito e da sociologia e tem por objetivo trazer uma visão sobre como os meios adequados de solução de conflitos podem ampliar o acesso à justiça, este visto como direito fundamental. A pacificação de conflitos foi contextualizada para o momento histórico que se vive no Brasil, tendo por base sua constituição, seus princípios políticos, sociais e econômicos. A mediação - autocomposição - e a arbitragem - heterocomposição - são meios alternativos não estatais para a solução de conflitos, mas são sistemas jurídicos, justos e utilizados em todo o mundo. Conhecer destes modelos, das políticas públicas e sua aplicação no Brasil e em outros países pode contribuir para uma visão mais ampliada do quanto a sociedade privada pode participar e facilitar o acesso à justiça para melhorar as condições de vida do homem em sociedade.

Palavras chave: Acesso à justiça. Direito fundamental, Mediação. Pacificação.

\section{EL ACCESO A LA JUSTICIA COMO DERECHO FUNDAMENTAL}

\section{ABSTRACT}

Este artículo se realizó a través de una investigación sobre legislación y trabajos bibliográficos en el área del derecho y la sociología y tiene como objetivo aportar una visión sobre cómo los medios adecuados de resolución de conflictos pueden ampliar el acceso a la justicia, este visto como un derecho fundamental. La pacificación de los conflictos se contextualizó para el momento histórico de Brasil, a partir de su constitución, sus principios políticos, sociales y económicos. La mediación - autocomposición - y el arbitraje - heterocomposición - son medios alternativos no estatales para resolver conflictos, pero son sistemas legales, justos y usados en todo el mundo. Conocer estos modelos, las políticas públicas y su aplicación en Brasil y otros países puede contribuir

* É advogado, mestre em Direito Político e Econômico e pós-graduado em Direito Empresarial pela Universidade Presbiteriana Mackenzie; pedagogo, pós graduado em Planejamento, Gestão e Implementação de cursos à distância pela Universidade Federal Fluminense, contador e professor da Universidade Metodista de São Paulo; fundador e presidente do TASP - Centro de Mediação e Arbitragem de São Paulo; Mediador de negociação coletiva credenciado pelo Ministério do Trabalho em 2005; Mediador credenciado pelo Tribunal de Justiça de São Paulo. Autor do livro "Arbitragem, mediação e conflitos coletivos do trabalho" (2005). Currículo lattes disponível em http://lattes.cnpq.br/7572447968259384 
a una visión más amplia de cuánto puede participar la sociedad privada y facilitar el acceso a la justicia para mejorar las condiciones de vida del hombre en la sociedad.

Palabras clave: Acceso a la justicia. Derecho fundamental. Mediación. Pacificación.

\section{INTRODUÇÃO}

O propósito do presente artigo é apresentar como o direito fundamental de acesso à justiça pode ser atendido por meios alternativos não estatais. O Brasil, como Estado democrático de direito, vive uma ideologia neoliberal que impõe modelos de relações jurídicas que podem ter seus conflitos dirimidos por meios privados, em especial pela mediação e pela arbitragem.

A Resolução 125 do Conselho Nacional de Justiça adotou uma nova modalidade de pacificação de conflitos - mediação - e desta forma estimulou este modelo que passou a ser utilizado em todos os tribunais do país. O Brasil assumiu esse compromisso constitucional de distribuir justiça pela autocomposição deixando o Poder Judiciário comprometido com este novo modelo de acesso à justiça.

Hoje muitas legislações apontam nesta direção e a utilização dos Meios Adequados de Solução de Conflitos - MASCs - é uma realidade na administração pública e na sociedade privada.

Este modelo de acesso à justiça é utilizado em todo o mundo e o Brasil quando adota esta forma de pacificação de conflitos fica dentro dos sistemas mundiais que têm nos MASCs uma facilitação de negócios dentro de uma dinâmica econômica e social que atende ao modelo ideológico de produção e consumo. Assim, incluído neste sistema, o Brasil fica com sua organização compatível com os países mais desenvolvidos do mundo.

\section{O MODELO IDEOLÓGICO BRASILEIRO E O CONFLITO SOCIAL}

\section{O MODELO IDEOLÓGICO}

Para iniciarmos o estudo sobre a responsabilidade do Estado brasileiro para o cumprimento dos objetivos e princípios fundamentais precisamos sempre considerar o acesso à justiça como premissa da construção de uma sociedade livre, justa e solidária. Conhecer todos os meios de pacificação de conflitos admitidos pela nossa Lei maior é buscar garantir o desenvolvimento social e econômico nacional com respeito ao verdadeiro exercício da cidadania.

Em nosso estudo vamos conhecer os meios adequados de solução de conflitos sociais no Brasil, dentre os quais destacaremos a mediação e a arbitragem. Neste estudo é primordial que possamos entender primeiramente o contexto histórico e ideológico em que nossa sociedade vive e está submetida em razão dos princípios e direitos fundamentais previstos na Constituição Federal.

As condições sociais e econômicas de um país ou de uma comunidade sempre são determinadas pela ideologia existente, que irá impor a forma de vida e seus valores éticos/morais, além de determinar os rumos de sua economia. Esta análise 
deve ser feita necessariamente em determinado momento histórico. A partir desta análise poderemos entender o comportamento individual e coletivo do homem e suas práticas no meio social em que vive.

A ideologia que motiva o homem em sociedade irá, geralmente, determinar o seu comportamento, as suas necessidades, possibilidades e o tipo de conflito a que ele está sujeito com maior ou menor intensidade no decorrer das relações sociais e jurídicas que estabelece no convívio com a sociedade civil e com Estado.

A proposta deste trabalho é estudar a possibilidade de aplicação de meios alternativos não estatais de solução de conflitos, também conhecidos como meios adequados para solução de controvérsias (negociação, mediação, conciliação e arbitragem), dentro do contexto ideológico existente na sociedade brasileira a partir de sua Constituição Federal.

A Constituição Federal, carta magna na organização política, econômica e social do país, está apoiada no sistema capitalista, que admite a propriedade privada dos meios de produção, a livre iniciativa, a livre concorrência e consequentemente a divisão de classes. Assim, as relações de trabalho e as relações de consumo são as mais comuns, sendo que o consumo é pedra angular para o funcionamento e manutenção do sistema.

Neste modelo econômico, a empresa, como fonte de geração de riquezas, de trabalho e de tributos, impera soberana por estar no coração do sistema. Está na empresa a geração e a produção da riqueza, o lucro e a mais valia, o interesse do empresário, a ocupação da mão de obra e o emprego do trabalhador. O fato gerador dos impostos é a principal fonte de recursos para o Estado poder cumprir com suas propostas políticas.

O Brasil adotou o sistema neoliberal e, desta forma, a arrecadação tributária é basicamente a única fonte de renda do Estado para o cumprimento de suas metas/ propostas e para cumprir com suas obrigações em face da sociedade.

Neste contexto econômico, nossa ideologia se encerra no consumo como principal meio de subsistência e manutenção do sistema. A ideologia neoliberal globalizada adotou como princípio as ideias do economista Victor Lebow, que assim identificou os princípios que devem reger uma sociedade consumerista:

A nossa enorme economia produtiva exige que façamos do consumo nossa forma de vida, que tornemos a compra e uso de bens em rituais, que procuremos a nossa satisfação espiritual, a satisfação do nosso ego, no consumo. Precisamos que as coisas sejam consumidas, destruídas, substituídas e descartadas a um ritmo cada vez maior. ${ }^{1}$ (LEBOW. 1955, p. 07)

Assim, a sociedade brasileira vive em um sistema em que a busca de acumulação de bens, pela propriedade privada e pelos bens de consumo, está no centro dos interesses e das necessidades do homem em sociedade. Esta é a ideologia que motiva

1 Lebow, 1955. Victor Lebow foi um economista e analista estado unidense de varejo do século 20. Talvez mais conhecido pela sua cotação em relação à formulação do conceito de capitalismo de consumo. 
o homem dentro deste modelo econômico: a busca pela felicidade e pelo bem-estar no convívio social a partir do consumo de bens e serviços.

Os conflitos têm normalmente como fonte os diferentes interesses, necessidades e possibilidades a que o homem está sujeito em suas inter-relações sociais e, no caso brasileiro, os conflitos e a necessidade de pacificação estão dentro deste contexto ideológico, que é imposto e que é mantido pelo sistema.

Assim, podemos afirmar que a maior parte dos conflitos está relacionada aos modelos mais comuns de relações sociais e jurídicas que ocorrem dentro da sociedade brasileira: as relações de emprego (capital x trabalho) e as relações decorrentes do uso e alienação de bens e serviços, que são chamadas de relações de consumo².

Os conflitos decorrentes destes tipos de relação jurídica, como regra, são de natureza privada e, portanto, por serem questões relacionadas a direitos patrimoniais, podem ser solucionados por meios de pacificação extrajudiciais. Desta forma, a maior parte dos conflitos sociais não necessitam da intervenção direta do Estado como único caminho para a solução das controvérsias.

Neste cenário, temos uma possibilidade bastante ampla de utilização de sistemas adequados não estatais de pacificação, porém é certo que em todas estas relações poderão, em determinados momentos, haver o interesse público e, nestes casos, a intervenção estatal será indispensável.

Este é o sistema e o modelo ideológico sobre o qual debruçaremos nosso estudo quanto a utilização de meios adequados não estatais para a solução de conflitos sociais. Trataremos do tema em uma sociedade capitalista neoliberal, que acredita na economia gerida pelo privado com a mínima ingerência do Estado. Uma sociedade de consumo com privilégios para a propriedade privada e que convive com a divisão de classes ${ }^{3}$.

\section{O CONFLITO SOCIAL}

O homem, em toda sua trajetória, sempre viveu gregariamente, mas mesmo tendo a necessidade de viver em sociedade, em contextos sociais e econômicos diversos, sempre conviveu, em maior ou menor grau, com o conflito social.

O conflito surge, como regra, em razão das diferenças de poder econômico e de acesso às necessidades básicas ou criadas pelo meio social em que vive. $\mathrm{O}$ conflito surge de condições diferentes dentro de cada contexto histórico para cada homem, seja sob o aspecto individual, seja sob o aspecto coletivo. No convívio social, o homem conhece diferentes necessidades, possibilidades e interesses e estes são as principais razões que justificam o surgimento do conflito. Podemos falar em fontes de origem do conflito e desta forma citaremos as diferenças e as desigualdades como principais fontes.

2 Conselho Nacional de Justiça, Relatório Justiça em Números, 2018.

3 Constituição Federal - Artigo 170. A ordem econômica, fundada na valorização do trabalho humano e na livre iniciativa, tem por fim assegurar a todos existência digna, conforme os ditames da justiça social, observados os seguintes princípios: I - soberania nacional; II - propriedade privada; III - função social da propriedade; IV - livre concorrência; V - defesa do consumidor; (...) 
O poder ou a busca pelo poder também sempre surge como fonte de conflito. Então, podemos concluir que no convívio social a busca pelo poder e as diferenças que o homem impõe sobre o outro ou de um grupo sobre outro são as fontes que geram e fazem surgir os conflitos.

Para este nível de dificuldade e consequentes conflitos sociais, não podemos esperar que os meios adequados sejam capazes de atender a todas as necessidades da sociedade, mas podem ajudar os envolvidos a entender o problema para que possam pensar outras formas de buscar uma solução de forma individual ou coletiva, visando assim melhorar a condição de vida de todos com a minimização das diferenças econômicas.

As diferenças econômicas impõem outra diferença que faz gerar conflitos: as possibilidades. Dentro deste modelo ideológico, quanto mais recursos e mais acesso as pessoas tiverem, menos distanciamento haverá entre todos no convívio social. Isto vale para tudo: educação, saúde, transporte, habitação, lazer etc. Quanto maior for o recurso econômico, tanto melhor será a qualidade de vida e a possibilidade de acesso a estes constitucionais direitos sociais que implicam em verdadeira cidadania.

Por fim, outra fonte de conflito decorre de interesses diferentes que se estabelecem nas mais diversas relações sociais e jurídicas. Como regra, as pessoas se aproximam e se relacionam com interesses diferentes. Quando alguém quer vender, se relaciona com alguém que pretende comprar, isto vale para a prestação de serviços, a locação etc. A exceção a esta regra é o casamento e os contratos sociais para a formação de sociedades mercantis e entidades civis. Neste modelo de relação, em tese as pessoas querem a mesma coisa. Isto é tão verdadeiro que quando uma das partes passa a ter outro interesse, surge o conflito.

As pessoas, como vimos, se relacionam por interesses diferentes e quando acrescentamos a estas relações diferentes necessidades e possibilidades econômicas, aumentamos muito a possibilidade de controvérsias, que se estabelecem e precisam ser superadas para a organização do convívio social.

Assim, as principais fontes de conflito são as diferenças, que podem ser econômicas, culturais, ideológicas, religiosas, entre outras. Estas diferenças se expressam com o surgimento de diferentes necessidades, possibilidades e interesses.

Feitas estas observações sobre as principais fontes de conflito, queremos estabelecer um conceito importante sobre como o conflito está identificado dentro do sistema em um Estado democrático de direito. Para a organização social e jurídica, o conflito deve ser tratado como "pretensão resistida". Desta forma, sempre que alguém possui uma pretensão legítima de ser, ter, fazer ou deixar de fazer algo e alguém se coloca como impedimento e bloqueio para a possibilidade de acesso a este legítimo direito, estamos diante de um conflito.

A pretensão de ser, ter, fazer ou deixar de fazer algo deve estar respaldada pelo direito, já que, de acordo com nossa Constituição, ninguém está obrigado a fazer ou deixar de fazer senão em virtude de lei. Legítima a pretensão, haverá em nosso ordenamento jurídico meios e procedimentos para que este direito possa se 
realizar. Quando falamos dos MASCs, estamos falando de meios e de procedimentos legais que permitem o cumprimento e realização do direito pretendido fora dos procedimentos judiciais (processo judicial).

Concluímos este importante conceito de conflito com uma distinção igualmente importante que é a diferença entre conflito e litígio ${ }^{4}$. Se conflito é a pretensão resistida, litígio é a pretensão resistida levada ao conhecimento e eventual julgamento de terceiro, que tenha poder e força vinculante entre as partes envolvidas para fazer valer sua decisão. Portanto, todo processo judicial que verse sobre uma disputa sempre será chamado de litígio, enquanto que a controvérsia submetida previamente a um mediador ou um conciliador poderá ser um conflito, visto que o mediador, apesar de terceiro estranho à lide, não terá poder de decisão para impor às partes seu entendimento e sua jurisdição sobre o objeto litigioso.

O conflito social é a razão e a condição para se falar e se estudar os meios de pacificação. Quanto menos uma sociedade tiver diferenças, quanto menos diferentes forem os interesses deste grupo social, tanto menores serão os conflitos e tanto menor a necessidade de instrumentos de pacificação. No Brasil, no contexto histórico e ideológico contemporâneo, cada vez mais discutimos estes métodos e necessitamos de mais juízes, mediadores, árbitros, policiais e presídios. Esta condição está prevista em nossa Constituição como aspiração do povo brasileiro, porém, enquanto se mantiver e se ampliarem as diferenças sociais e econômicas, tanto mais conflitos sociais teremos.

\section{OS MEIOS ADEQUADOS DE PACIFICAÇÃO DE CONFLITOS E A AMPLIAÇÃO DO ACESSO À JUSTIÇA}

Identificados os conflitos, suas fontes e motivações sociais e econômicas, passamos a estudar e conhecer os meios adequados de pacificação de conflitos admitidos e incentivados pela Constituição Federal.

Tratar dos meios adequados de solução de controvérsias é também discutir o constitucional direito do acesso à justiça e da duração razoável do processo. A Resolução 125 do Conselho Nacional de Justiça - CNJ - promulgada em 29/11/2010, estabeleceu novos parâmetros para a solução de conflitos dentro dos procedimentos admitidos pelo Poder Judiciário. Neste contexto a mediação, a conciliação e a arbitragem são sistemas que podem ser tratados como meios eficazes e definitivos de satisfação jurisdicional e consequentemente são novas vias de acesso à justiça colocadas à disposição da sociedade.

Mauro Cappelletti (1988) ensina que a satisfação jurisdicional somente ocorre se forem satisfeitas as três ondas renovatórias de acesso à justiça, que são a assistência judiciária aos pobres; a representação dos interesses difusos e a necessidade de buscar novas formas de acesso aos mecanismos jurídicos ${ }^{5}$ (CAPPELLETTI, 1988, p. 25).

Para que o Brasil tenha uma sociedade pacífica e livre de controvérsias, a pacificação de conflitos deve ser vista como aspiração constitucional. O acesso à justiça

\footnotetext{
Litígio, do latim litigiu é o pleito, demanda, disputa; contenda; questão.

CAPPELLETTI, 1988, p. 25.
} 
e a duração razoável do processo são necessidades típicas que se tem na busca da pacificação social.

Estes direitos constitucionais não devem ser tratados exclusivamente pelo Estado, via Poder Judiciário, mas também podem e devem ser atendidos com a utilização dos métodos previstos pelos MASCs. A busca pela paz e pela justiça social deve também ser prática de responsabilidade da sociedade e das suas instituições e, desta forma, a pacificação de conflitos não deve ser tratada como obrigação exclusiva do Estado.

A mediação e a arbitragem são instrumentos legalmente instituídos e que estão à disposição da sociedade para que se tornem conhecidos e efetivos meios de pacificação de conflitos sociais e sejam tratados como exercício de cidadania.

A mediação foi acolhida como procedimento pelo Poder Judiciário com a Resolução 125/2010 do CNJ e por esta razão foram criados centros de mediação e conciliação em todos os tribunais do país. Esta mesma resolução instituiu regras para a formação de profissionais que estão sendo capacitados como mediadores e conciliadores para que esta prática venha a compor e ampliar os meios de acesso à justiça previstos em nossa Constituição.

A arbitragem, já prevista em nosso direito de forma moderna e atualizada dentro dos atuais modelos globalizados de solução de conflitos desde $1996^{6}$ (CARMONA, 2004, p 20), também ganhou importância e espaço nos últimos anos tendo sido fortalecida pela Lei 13.129/15. A arbitragem tende a ser um procedimento cada vez mais utilizado, pois vem sendo adotada como disciplina nos cursos de graduação em direito e em outros cursos como contabilidade e administração, em todo o Brasil.

A Constituição Federal garante a todos os brasileiros e estrangeiros domiciliados no país o acesso à justiça e a duração razoável do processo, além dos meios que garantam a celeridade de sua tramitação.

A Resolução 125/10 do Conselho Nacional de Justiça tem por objetivo aumentar a celeridade na solução de conflitos com a utilização da mediação, além do sistema judicial de solução de controvérsias, que decorre de decisões judiciais adjudicadas aos jurisdicionados.

A melhoria das condições de pacificação de conflitos passa por uma mudança cultural que implica na quebra de alguns paradigmas e mudanças no sistema. Essas mudanças não interessam para alguns grupos que por questões econômicas, políticas, corporativistas impedem o Estado brasileiro de promover o avanço necessário para um verdadeiro movimento em favor da cultura da paz e para se conseguir desenvolvimento social e econômico.

O Poder Judiciário encontra cada vez mais dificuldade para cumprir com seu dever constitucional de pacificar conflitos e manter a paz social. As constantes alterações legislativas e administrativas adotadas com o objetivo de dar mais celeridade aos processos nem sempre conseguem produzir o efeito necessário,

6 CARMONA, 2004, p 20. 
fato que gera insatisfação da sociedade e dos operadores do direito. ${ }^{7}$ (MARTINS, 2015, p. 79).

O direito de acesso à justiça não se limita ao acesso ao Poder Judiciário, mas sim ao resultado jurisdicional almejado. A ampliação de possibilidade de reclamações ou de ingresso de medidas judiciais não é suficiente para atender às necessidades da sociedade e à letra constitucional. Por isso, surge a importância de ampliação de meios e métodos de pacificação de conflitos e não de processos, procedimentos ou de lugares onde se possa reclamar. O importante e necessário é um resultado jurisdicional efetivo e satisfativo ${ }^{8}$. (GRINOVER, 1990, p. 12).

A mediação e a arbitragem representam verdadeiros meios de ampliação de acesso à justiça, pois permitem à sociedade que resolva suas pendências de forma juridicamente definitiva e segura, sem a intervenção direta do Estado.

Muitos países já utilizam este modelo com resultados bastante satisfatórios para a sociedade e para os operadores do direito. A solução extrajudicial de controvérsias é necessária e representa um avanço nas relações sociais e econômicas de um Estado democrático de direito.

\section{OS MASCS E AS POLÍTICAS PÚBLICAS}

A mediação foi adotada como instrumento de pacificação de conflitos pelo Poder Judiciário por meio da Resolução 125 do Conselho Nacional de Justiça, a partir de outubro de 2010, e foi levada a efeito na gestão do ministro Cesar Peluso, sob a coordenação do professor Kazuo Watanabe e da dra. Valéria Lagrasta. Esta resolução trouxe uma nova visão e um novo procedimento - mediação - para o Poder Judiciário, enquanto órgão responsável pela pacificação de conflitos sociais. Destacamos aqui parte do discurso de posse do ministro do Supremo Tribunal Federal, Antonio Cezar Peluso (PELUSO, 2010, p. 9):

\footnotetext{
É preciso institucionalizar, no plano nacional, esses meios como remédios jurisdicionais facultativos, postos alternativamente à disposição dos jurisdicionados, e de cuja adoção o desafogo dos órgãos judicantes e a maior celeridade dos processos, que já serão avanços muito por festejar, representarão mero subproduto de uma transformação social ainda mais importante, a qual está na mudança de mentalidade em decorrência da participação decisiva das próprias partes na construção de resultado que, pacificando, satisfaça seus interesses. (pg. 09) (g.n.)
}

O Poder Judiciário sempre tratou a pacificação de conflitos por meio de decisões adjudicadas e impostas por meio de sentenças e decisões judiciais. A partir dessa resolução, o Judiciário passou a entender a pacificação de conflitos também pela via autocompositiva da mediação, que é uma solução obtida pelas próprias partes com a ajuda de um mediador.

\footnotetext{
MARTINS, 2015, p. 79.

8 GRINOVER, 1990, p. 12.
} 
Para a realização prática desta medida passaram a ser instalados cursos de capacitação para mediadores e conciliadores e houve a criação de Centros Judiciários de Solução de Conflitos (CEJUSC) em vários pontos do país, muitas vezes dentro do próprio fórum e outras vezes em locais destinados para este fim.

Até a presente data, a maior parte dos mediadores que atuam nos CEJUSC são voluntários. São eles advogados, leigos, profissionais aposentados, psicólogos, estagiários e outras pessoas que se dispõem a atuar empregando seu tempo e seu trabalho em prol da sociedade.

Os locais onde se realizam estas mediações, em que pese a boa vontade dos envolvidos, nem sempre estão equipados com os recursos materiais e humanos necessários para que este modelo efetivamente cumpra o que se propõe. As pessoas envolvidas nem sempre estão capacitadas para realização de tarefa tão complexa, e muitas vezes não há dentro da organização dos procedimentos (CEJUSC ou juizados especiais) tempo suficiente para a realização dos trabalhos.

A divulgação do sistema de pacificação de conflitos deve ocorrer em todos os lugares onde se desenvolvem lideranças como em centros culturais, acadêmicos e religiosos. Uma ação neste sentido iniciará uma mudança de paradigma a partir de formadores de opinião que com legitimidade e confiança em suas comunidades passarão a atuar na solução de controvérsias ou na prevenção de litígios que em seus meios venham a surgir.

A cultura da paz que prega nossa Constituição e agora também promulgada pelo CNJ (Conselho Nacional de Justiça) exige um sistema bem estruturado para que as pessoas possam escrever a história de suas vidas solucionando seus problemas em suas comunidades, sem a necessidade da carga de um processo judicial.

O incentivo às práticas de pacificação de controvérsias por instituições privadas está previsto na Resolução 125 como forma de se evoluir no modelo ${ }^{9}$ e afastar a cultura da desconfiança e a proteção do sistema corporativista de mercado.

\section{O ACESSO À JUSTIÇA POR MEIOS ALTERNATIVOS NO DIREITO COMPARADO}

A utilização de meios alternativos não estatais, também chamados de meios adequados para a solução de controvérsias, é prática comum em muitos países e

\footnotetext{
9 Resolução 125. Art. $5^{\circ}$ O programa será implementado com a participação de rede constituída por todos os órgãos do Poder Judiciário e por entidades públicas e privadas parceiras, inclusive universidades e instituições de ensino. Artigo $6^{\circ}$. Para desenvolvimento dessa rede caberá ao CNJ: $\mathrm{V}$ - buscar a cooperação dos órgãos públicos competentes e das instituições públicas e privadas da área de ensino, para a criação de disciplinas que propiciem o surgimento da cultura da solução pacífica dos conflitos, bem como que, nas Escolas de Magistratura, haja módulo voltado aos métodos consensuais de solução de conflitos, no curso de iniciação funcional e no curso de aperfeiçoamento; VII - realizar gestão junto às empresas, públicas e privadas, bem como junto às agências reguladoras de serviços públicos, a fim de implementar práticas autocompositivas e desenvolver acompanhamento estatístico, com a instituição de banco de dados para visualização de resultados, conferindo selo de qualidade; Artigo $7^{\circ}$ - VI - propor ao Tribunal a realização de convênios e parcerias com entes públicos e privados para atender aos fins desta Resolução. Disponível em $<\underline{\text { ht- }}$ tps://atos.cnj.jus.br/atos/detalhar/atos-normativos?documento=156>. Acesso em: 21 ago.2020
} 
tem se mostrado como modelo útil e eficiente, como trataremos a seguir. O Brasil também deve entender e se utilizar destas formas de solução de conflitos para que nossa sociedade fique equiparada aos países mais desenvolvidos e que estas práticas venham fazer parte da cultura da paz pregada na Constituição Federal.

O Desembargador Sérgio Bittencourt (2011) citou que nos Estados Unidos a mediação é obrigatória, especialmente em determinados Estados americanos, onde a ação só será conhecida pelo magistrado se ficar demonstrado que antes do ajuizamento da demanda as partes passaram pela mediação ${ }^{10}$.

Em Portugal, desde 2013, existe a Lei da mediação que visa a utilização da mediação na pacificação de conflitos, independentemente de sua natureza, com vistas especialmente às relações civis e comerciais ${ }^{11}$. A nova legislação em Portugal visa unificar num único diploma regimes que, até a sua publicação, se encontravam dispersos. A Lei de Mediação visa contribuir para uma maior informação e divulgação da mediação e, consequentemente, para uma maior utilização deste mecanismo, oferecendo aos cidadãos e às empresas uma solução complementar à via judicial, no quadro de uma oferta do sistema de justiça plural e ajustada em função do tipo de litígio ${ }^{12}$.

Os mediadores portugueses devem passar por um processo de preparação para que possam ser aceitos e ser válidas as atas por eles lavradas. Tal formação ocorre no mais das vezes fora do eixo estatal dentro do regime português, que não tem um organismo público para a formação de mediadores, sendo estes formados por instituições privadas. O Ministério da Justiça português confere a devida credibilidade aos cursos que esses organismos privados disponibilizam. A credibilidade exige um determinado número de horas de formação, um determinado método de ensino e um conteúdo programático específico, respeitando, ainda, a portaria aprovada para o efeito.

Os organismos privados que são responsáveis pela formação de mediadores - que são candidatos a integrar as listas organizadas pela DGPJ (Direção Geral da Política de Justiça) - têm de respeitar os critérios de formação. O programa de formação assegura que esses mediadores têm capacidade e idoneidade profissional para resolver litígios familiares, laborais, penais e civis através da mediação ${ }^{13}$.

10 Fonte: Disponível em: <https://www.cnj.jus.br/aprovada-ampliacao-do-sistema-de-mediacao-e-conciliacao-do-tjdft/ > . Acesso em: 21 ago.2020.

11 “A Lei n. . 29/2013, de 19 de abril (Lei da Mediação) consagra os princípios gerais aplicáveis à mediação realizada em Portugal, independentemente da natureza do litígio que seja objeto de mediação; estabelece o regime jurídico da mediação civil e comercial; o regime jurídico dos mediadores e dispõe ainda sobre o regime jurídico dos sistemas públicos de mediação. Neste sentido, este diploma normativo, atento o seu alcance transversal e a sua abrangência no domínio de toda a mediação ocorrida em Portugal, assume-se como uma verdadeira lei de enquadramento da mediação nacional, no panorama dos meios de resolução alternativa de litígios". Disponível em: <https://e-justice.europa.eu/content_mediation_in_member_states-64-pt-maximizeMS-pt. do?member=1>. Acesso em: 21 ago.2020.

12 Disponível em: <https://vymaps.com/PT/Centro-Privado-De-Mediac-o-De-Conflitos-588554011187410/>. Acesso em: 21 ago. 2020.

13 Disponível em: <https://e-justice.europa.eu/content_mediation_in_member_states-64-pt-pt. do?member=1>. Acesso em: 4 ago. 2020. 
A experiência de outros países tem demonstrado que, por meio de estruturas mais simplificadas, como é o caso da mediação, tanto a prevenção como a solução de conflitos poderão ser obtidos com maior informalidade, celeridade e acessibilidade, quer para os particulares, quer para as empresas. Para promover o recurso a este meio de solução alternativa de litígios, revelou-se essencial a criação de um suporte legislativo que congregasse as regras basilares da mediação, quer no nível dos seus princípios, das regras deontológicas aplicáveis aos mediadores, quer no plano do processo e do procedimento da mediação ${ }^{14}$.

$\mathrm{Na}$ Argentina também se tem um forte sistema de pacificação de conflitos pela via da mediação, sendo certo que a sua organização admite a mediação em conflitos comerciais, trabalhistas, cíveis e especialmente no direito de família. A tentativa prévia de conciliação na Argentina é condição obrigatória para o acesso à via judiciária, assim como ocorre no Peru e no Uruguai. ${ }^{15}$

Na cultura de muitos países, como China e comunidades judaicas, líderes de comunidades ou líderes religiosos desempenham papel decisivo na pacificação de conflitos ${ }^{16}$. (BONDER, 2010).

A União Europeia promove ativamente modos de Resolução Alternativa de Litígios (RAL) como, por exemplo, a mediação. A Diretiva Mediação, que diz respeito à mediação em matéria civil e comercial, em vigor desde 2011, se aplica aos seus EstadosMembros. ${ }^{17} \mathrm{Na}$ comunidade europeia o incentivo à mediação é pleno e organizado dentro do sistema de pacificação de conflitos.

Ao incentivar o recurso à mediação, estáse a facilitar a resolução dos litígios e a contribuir para evitar a preocupação, a perda de tempo e os custos inerentes aos processos judiciais, permitindo assim que os cidadãos exerçam de forma eficaz os direitos que lhes assistem.

A Diretiva «Mediação» é aplicável aos litígios transfronteiriços em matéria civil e comercial em que pelo menos uma das partes tenha domicílio num EstadoMembro distinto do Estado-Membro de qualquer das

14 Em Portugal existe um organismo governamental centralizado responsável pela regulação da mediação pública - a Direção-Geral da Política de Justiça (DGPJ). O site da DGPJ contém grande parte das informações disponíveis sobre mediação pública, bem como sobre outros meios de resolução alternativa de litígios. A DGPJ não informa sobre a forma de encontrar um mediador, mas dispõe de listas de mediadores. Uma vez tomada a decisão de recorrer à mediação, nos termos da legislação relativa à mediação pública, é selecionado automaticamente um mediador. Disponível em <https://e-justice.europa.eu/content_mediation_in_member_states-64-pt-pt.do?member=1>. Acesso em: 4 ago. 2020.

15 Na Argentina o processo não terá prosseguimento no Fórum sem passar pela mediação. Se chegar à mão do juiz este determinará seu envio ao mediador que fará a mediação e o relatório desta. Se a mediação resultar num acordo, este será homologado e o processo arquivado. Se não houver acordo, o relatório do mediador irá ao juiz, que dará prosseguimento ao processo. Nem todo tipo de processo dependerá da mediação prévia, que até então é extrajudicial. Ficam fora dela os processos criminais, divórcio, investigação de paternidade, interdição, trabalhistas, falimentares, pátrio poder, medidas cautelares. Não se submetem à mediação também as causas em que o Estado seja parte. Roque, 2014.

16 BONDER, 2010.

17 Directiva 2008/52/CE do Parlamento Europeu e do Conselho, de 21 de maio de 2008, relativa a certos aspectos da mediação em matéria civil e comercial. 
outras partes à data em que estas decidam, por acordo, recorrer à mediação ou em que a mediação seja ordenada por um tribunal.

O principal objetivo deste instrumento jurídico consiste em incentivar o recurso à mediação nos EstadosMembros. ${ }^{18}$

Importante observar que se o Brasil pretende efetivamente fazer valer a prática da mediação em nossa sociedade deve estabelecer regras e criar estrutura física e formação de pessoas que possam ser capazes de entender o objetivo e a importância social destas normas e fazê-las cumprir, como ocorre na comunidade europeia.

Para esse efeito, na Europa a diretiva estabelece cinco regras substantivas:

- Obriga os EstadosMembros a incentivarem a formação de mediadores e a garantirem uma mediação de elevada qualidade.

- Confere a cada juiz o direito de convidar as partes em litígio a recorrerem primeiro à mediação, se o considerar adequado atendendo às circunstâncias do caso.

- Prevê a possibilidade de os acordos obtidos por via de mediação serem declarados executórios se ambas as partes o solicitarem. $\mathrm{O}$ caráter executório pode ser estabelecido, por exemplo, mediante homologação de um tribunal ou certificação efetuada por um notário público.

- Assegura a condução da mediação num clima de confidencialidade. Neste sentido, dispõe que num futuro litígio entre as partes na mediação, os mediadores não podem ser obrigados a prestar depoimento em tribunal sobre o que ocorreu durante a mediação.

- Garante que as partes não perdem a possibilidade de levar o caso a tribunal em resultado do tempo gasto na mediação: os prazos de instauração da ação judicial suspendemse durante a mediação. ${ }^{19}$

Assim, podemos observar e considerar que no Brasil há muito o quê se fazer em prol do sistema dos meios alternativos para que estes venham a ser adotados não somente na organização judicial, mas na cultura jurídica do povo brasileiro.

O tema acesso à justiça vem ganhando espaço em todo o mundo com clara demonstração de que o Estado não necessita intervir em todos os conflitos como ente adjudicador de decisões, mas como órgão que viabiliza o diálogo e permite que as pessoas e as instituições resolvam seus próprios problemas com compromisso e responsabilidade, sem que seja necessária a intervenção do Estado em todas as relações.

Quando o Brasil timidamente acena para a possibilidade de pacificar conflitos pela mediação, este não está inovando, está na verdade se adequando a práticas milenares utilizadas e valorizadas em todos os tempos e em todos os lugares do mundo.

18 Disponível em: <https://e-justice.europa.eu/content_eu_overview_on_mediation-63-pt.do. Acesso em: 4 ago. 2020.

19 Disponível em: <https://e-justice.europa.eu/content_eu_overview_on_mediation-63-pt.do. Acesso em: 4 ago. 2020. 
Por isso a importância de que se desenvolvam no país técnicas e práticas de mediação em diversos níveis da aprendizagem para que se tenha uma cultura voltada para a paz e não uma cultura voltada para a litigiosidade. Cursos dos mais diversos níveis devem ser ministrados para a formação de mediadores, isto entre técnicos, religiosos, bacharéis, mestres, doutores, além de cursos de extensão.

A sociedade brasileira precisa se desenvolver e criar novas perspectivas de pacificação de conflitos para atender a necessidade da sociedade brasileira e a aspiração prevista em nossa Constituição.

\section{CONCLUSÃO}

O estudo de qualquer condição social deve ser validado pelo momento histórico sobre o qual irá se debruçar o estudo e a pesquisa. Assim, considerando estas condições, o presente artigo teve por objetivo demonstrar como os meios alternativos podem ser úteis na ampliação do acesso à justiça.

As políticas públicas também fazem parte do cumprimento da carta constitucional e a utilização dos meios adequados de solução de conflitos - mediação e arbitragem - coloca o Brasil nas mesmas condições de países desenvolvidos, que tratam da pacificação de conflitos com a mesma dinâmica das relações sociais e econômicas vividas no mundo globalizado.

\section{BIBLIOGRAFIA}

BITENCOUT, (2011) . Aprovada ampliação do sistema de mediação e conciliação do TJDFT Disponível em: <https://www.cnj.jus.br/aprovada-ampliacao-do-sistema-de-mediacao-e-conciliacao-do-tjdft/ > . Acesso em: 21 ago.2020.

BONDER, Nilton. O segredo judaico de resolução de problemas - lídiche kop. Rio de Janeiro: Rocco, 2010.

BRASIL. Constituição da República Federativa do Brasil: promulgada em 5 de outubro de 1988.

CAPPELLETTI, Mauro. GARTH, Bryant. Acesso à justiça. Tradução de Ellen Gracie Northfleet. Porto Alegre: Sérgio Antonio Fabris, 1988

CARMONA, Carlos Alberto. Arbitragem e Processo. Um comentário à Lei n. 9.307/1996. 2. ed. rev., atual. e ampl. São Paulo: Atlas, 2004.

Conselho Nacional de Justiça. Relatório Justiça em Números 2018: ano-base 2017. Brasília: CNJ, 2018. Disponível em: <https://www.cnj.jus.br/wp-content/uploads/2011/02/8d9faee7812d35a58cee3d92d2df2f25.pdf >. Acesso em: 10 ago. 2020.

FERNANDES, Francisco; LUFT, Celso Pedro. Dicionário Brasileiro Globo. 56. ed. São Paulo: Globo, 2003.

GRINOVER, Ada Pelegrini. A crise do Poder Judiciário. Revista da Procuradoria Geral do Estado de São Paulo, n. 34, p. 11-26, dez. 1990. 
LEBOW, Victor. Price Competition in 1955. Journal of Retailing, New York University School of Retailing, v. XXXI, n. 1, Spring, 1955.

MARTINS. José Celso. Arbitragem mediação e conflitos coletivos do trabalho. São Paulo: Ed. do autor, 2005.

MARTINS, José Celso. Direitos fundamentais - Acesso à justiça e duração razoável do processo. Revista do Curso de Direito da Faculdade de Humanidades e Direito, v. 12, n. 12, p. 79, 2015.

PELUSO, Antonio Cezar. Posse na presidência do Supremo Tribunal Federal. 23 abr. 2010. Disponível em: <http://www.stf.jus.br/arquivo/cms/noticiaNoticiaStf/anexo/discursoPeluso.pdf>. Acesso em: 10 ago. 2020.

PORTUGAL, 2013. Lei n. ${ }^{\circ}$ 29/2013 (Lei da Mediação).

ROQUE, Sebastião José. O sistema argentino de mediação é fonte inspiradora do brasileiro. Juiz de Fora: Universo Jurídico, ano XI, 05 fev. 2014. 